\title{
Perceiving Excitation Characteristics from Interactions between Field Road and Vehicle via Vibration Sensing
}

\author{
Yuansheng Cheng, ${ }^{1,2}$ Xiaoqin $\mathrm{Li} \mathbb{D}^{1,2}$ Xiaolan Man, ${ }^{1,2}$ Feifan Fan, ${ }^{1,2}$ and Zhixiong $\mathrm{Li}^{3}$ \\ ${ }^{1}$ School of Mechanical Electrification Engineering, Tarim University, Alar 843300, Xinjiang, China \\ ${ }^{2}$ Key Laboratory of Modern Agricultural Engineering, Tarim University, Alar 843300, Xinjiang, China \\ ${ }^{3}$ Yonsei Frontier Lab, Yonsei University, 50 Yonsei-ro, Seodaemun-gu, Seoul 03722, Republic of Korea \\ Correspondence should be addressed to Xiaoqin Li; 827625576@qq.com
}

Received 15 January 2021; Revised 21 February 2021; Accepted 17 March 2021; Published 5 April 2021

Academic Editor: Wen LIU

Copyright (C) 2021 Yuansheng Cheng et al. This is an open access article distributed under the Creative Commons Attribution License, which permits unrestricted use, distribution, and reproduction in any medium, provided the original work is properly cited.

\begin{abstract}
When agricultural vehicles operate in the field, the soft road excitation makes it difficult to measure the vehicle vibration. A camera-accelerator system can solve this issue by utilizing computer vision information; however, the relationship between the field road surface and the vehicle vibration response remains an unsolved problem. This study aims to investigate the correlation of the soft road excitation of different long-wave surfaces with the vehicle vibration response. Vibration equation between the vehicle and soft road surface system was established to produce an effective roughness model of the field soft road surface. In order to simulate the vehicle vibration state under different long-wave road surfaces, the soil rectangular pits with 21 kinds of different spans and depths were applied to the road surfaces, and a tractor vibration test system was built for vibration test. The frequency spectrum analysis was performed for the vibration response and the roughness signals of the road surfaces. The results showed that coefficient $\left(R^{2}\right)$ of frequency correlation between the roughness excitation and the original unevenness at the excitation point at the rear end of the rectangular soil pit fell within 0.9641 0.9969. The main frequency band of the vibration response fell within $0 \sim 3 \mathrm{~Hz}$, and the phenomenon of quadruple frequency existed. The correlation of roughness excitation with quadruple frequency fell within $0.992165 \sim 1$. The primary excitation points were located at the rear end of the rectangular soil pit. In addition, it also indicated that when the vehicle was driven without autonomous power, the vehicle vibration frequency mainly depended on the excitation frequency of the field road surface and the frequency at the maximum vehicle vibration intensity was 2 or 3 times of that at the maximum field soft road excitation. These findings may provide a reference for optimal design of vibration reduction and control for agricultural vehicles.
\end{abstract}

\section{Introduction}

In recent years, agricultural mechanization in china has been improved to a new higher level, followed by an increase in the application of agricultural vehicles [1]. Vehicle vibration will be caused by soil excitation during its operation, which will cause damage of parts, reduce the service life of vehicles [2], and also cause damage to the driver's body [3]. Meanwhile, it will aggravate soil compaction, affect the growth of crop roots [4], and ultimately reduce the yield [5]. As the road surface will be compressed and deformed during the vehicle is driven in the field, a wheel envelope will be formed on the soft road surface if it is featured with short wavelength. This will increase the relative damping between wheel and ground to form buffer [6], making it difficult to cause vehicle vibration. Therefore, long-wave road surface (such as gully and ridge road surface) in field is an important factor causing vehicle vibration [7]. Thus, it is of practical significance to exploring the correlation between different excitation features of long-wave road surface and vehicle vibration response.

The features of road surface excitation mainly depend on road roughness. The excitation features of highway hard road surface can be evaluated by measuring the shape and size of the road surface [8]. The measurement methods generally include contact measurement method, noncontact 
measurement method, and dynamic response measurement method [9]. For example, Bidgoli [10], Kheirati [11], and Putra [12] all measured the road surface with a noncontact measuring device and analyzed excitation features of the road surface, which provided a reference for the measurement of roughness of the hard road surface. Xue [13] and Shi [14] established vibration equation of vehicle-road surface system, analyzed vehicle vibration response signal under pothole road surface by using dynamic response measurement method, and calculated the size of pothole in the road, which provided great help for road maintenance. However, soil is a combination of solid, liquid, and gas phases [15]. When it is under pressure, it will be deformed. So, the shape of field soft road surface cannot be directly used as an excitation source for measurement. In the 1990s, research results of Zheng Research Group of Jilin University showed that interaction between soft road surface and wheels will make soft road surface deformed [16, 17], which makes soft road surface at different roughnesses before, at the moment of, and after compression by tires. Domestic scholars call displacement excitation of soft road surface to wheels in the form of a certain roughness as effective roughness. It is generally believed that effective roughness is the real excitation to vehicle [18-20]. Meanwhile, a set of soft road surface roughness test device was designed for measuring original roughness, effective roughness, and rutting roughness [18]. The empirical formula of effective roughness was obtained by combining the features of soil and wheels [20].

There are many researchers who take the effective roughness of soft soil pavement as the excitation input to explore the vibration characteristics of tractors. For example, Zhao [7] designed a set of vibration test system to measure the nonuniformity of paddy field bottom layer combined with rice transplanter. The results show that the nonuniformity of paddy field bottom layer is grade A pavement. The vibration characteristics of tractor are analyzed, which provide a new way for the design of paddy field agricultural machinery and the research of interaction mechanism between agricultural machinery and soil. Fan [21] selected a small sugarcane harvester combined with a vibration test system for vibration test with the random road surface in the field as the input, analyzed the vibration signals of the sugarcane harvester, and solved the excitation characteristics of the effective roughness of the road surface in the field. It is verified that the effective roughness of the soft road surface in the field has a great influence on the vibration of the harvesting cutter head of the sugarcane harvester. Zhu designed a test system of irregularity to measure the ups and downs of the hard bottom layer under paddy fields [22]. A tire-wet and soft paddy field soil system model is established to analyze the vibration characteristics of tractors. The results show that compared with the dirt road without vegetation coverage, the displacement transmission rate of front and rear wheels, pitch vibration, and vertical vibration of the fuselage all decrease [23]. Cutini [24] selected three tractors to install three-axis acceleration sensors at the seats and carried out vibration test combined with six kinds of field roads. The results show that the $X, Y$, and $Z$ axes responses of the sensor are all in the low-frequency range, and the longitudinal vibration response is highly correlated with the vertical displacement. It shows that the longitudinal comfort depends to a large extent on the vertical motion of the tractor. The above scholars have all taken random soft road surface as input excitation to explore the characteristics of tractor vibration and provided basis for the design of tractor vibration absorption system and real-time detection of road surface excitation characteristics. However, the tractor has too many degrees of freedom, which would lead to mutual interference in the actual movement process and reduce the accuracy in the vibration test process. At the same time, the frequency domain distribution of random soft road excitation is wide, which makes it difficult to accurately express the vibration characteristics of tractors under specific wavelength excitation.

In this study, a test method of tractor vibration is used to explore the correlation between the excitation characteristics of field soft pavement with different wavelengths and tractor vibration by the abovementioned concept of effective roughness. We firstly use the vibration acceleration sensor to explore the vehicle responses and then use the subjective evaluation to find the correlation. Vibration tests are carried out on a specific pavement by setting up rectangular pit with various sizes in the soil tank laboratory, simulating soft soil pavements with different wavelengths, and a single-degree-of-freedom vibration test system is used to avoid the interference caused by the negative effect of unexpected degrees of freedom of the tractor. An effective roughness model is established based on the vibration equation of the tractor-ground system. The frequency spectrum and relevant statistical analysis of the effective roughness and vibration acceleration signals are carried out to obtain the excitation frequency band of the soft pavement, the vibration frequency band of tractor, and the excitation characteristics of the vibration intensity and effective roughness, in order to reveal the correlation between the ground excitation characteristics and tractor vibration characteristics. When driving on a soft road, the longer and shorter wavelengths can cause the space movement of the vehicle, which makes it hard to determine the effective wavelength range from the vibration sensors. Therefore, the binocular event camera is fixed on the vibration test system to perform vibration test on the constructed field road, combining with the three-dimensional spatial motion signal measured by the visual mileage calculation method to synthesize and analyze the one-dimensional vertical displacement signal of the vehicle. By combining the image and vibration measurements, it is possible to obtain the short-wave and long-wave ranges of the pavement and explain the vehicle-soft road interaction. This paper will focus on the correlation between the excitation of the soft pavement and vehicle vibration. The contribution of this work is to provide a basis for real-time detection of the excitation characteristics and determine the wavelength range of the soft pavement, which will provide a basis for effective vehicle vibration control. 


\section{Materials and Methods}

\subsection{Test Materials}

2.1.1. Test Instruments and Equipment. The single-degreeof-freedom (SDOF) vibration test system is shown in Figure 1 . The tire is $825 \mathrm{R} 16$ all-steel radial tire of Mountaintech with an air pressure of $0.5 \mathrm{MPa}$. The acquisition instrument model is WS-5291, the signal amplifier model is WS-2401, the signal acquisition software is Vib'SYS, and the acceleration sensor model is BZ1124, all of which are produced by Beijing Wavespectrum Science and Technology Co., Ltd. The sensitivity of the acceleration sensor in the $Z$-axis direction (vertical direction) is $6.234 \mathrm{pc} / \mathrm{ms}^{-2}$, the frequency response range is $0.2 \sim 8 \mathrm{kHz}$, and the total mass $m$ in the vertical direction of the wheel is $103.5 \mathrm{~kg}$.

The test site is the soil trough laboratory of Tarim University (longitude: 81.297248 , latitude: 40.544428 ), and the soil is aridisols [25]. The area of the soil tank is $5 \times 30 \mathrm{~m}^{2}$, and the soil firmness of the trimmed site is measured. The model of the soil firmness instrument is TJSD-750-II. The test site is evenly divided into 7 columns and 3 rows, with a total of 21 sampling points. Each point is measured three times. The depths of the three measurements are $10 \mathrm{~cm}$, $20 \mathrm{~cm}$, and $30 \mathrm{~cm}$, respectively. The measured data are shown in Table 1.

Set the depth and span of the rectangular pit as variables. The depth is $10 \mathrm{~cm}, 20 \mathrm{~cm}$, and $30 \mathrm{~cm}$, respectively, which is used to change the amplitude of excitation. The spans are $10 \mathrm{~cm}, 20 \mathrm{~cm}, 30 \mathrm{~cm}, 40 \mathrm{~cm}, 50 \mathrm{~cm}, 60 \mathrm{~cm}$, and $70 \mathrm{~cm}$, respectively, which are used to change the excitation wavelength. The width is fixed at $30 \mathrm{~cm}$, and the distance between the two pits is fixed at $60 \mathrm{~cm}$. Ten rectangular pits with the same depth and span are one kind of pavement, which is divided into 21 kinds, as shown in Figure 2.

When a vehicle travels on a rectangular pit road surface, assuming that the rear end of the rectangular pit is the excitation point, the wavelength $\lambda$ of road surface excitation is defined as the sum of the spacing between the two pits and the span of the rectangular pit. Therefore, the equation $[7,27]$ for solving the excitation frequency of the actual rectangular pit pavement is

$$
f=n \times v,
$$

where $f$ is the spatial frequency, which is the reciprocal of the wavelength $\lambda$, and $v$ is the vehicle speed.

\subsection{Test Methods}

2.2.1. Vibration Test Method. In this paper, the tractor is used as the power to drive the vibration test bench. According to ISO5008, too slow speed of agricultural vehicles causes the phenomenon that it is difficult to cause excitation and too fast speed causes the nonlinear phenomenon [26]. Therefore, the vehicle speed is kept at $2 \mathrm{~km} / \mathrm{h}$ during the test process to ensure that the resonance of the test bench can be caused [24]. The excitation frequency is changed by changing the original pavement wavelength, and the vibration intensity is analyzed by test bench vibration acceleration signal. The sampling frequency is set to $2000 \mathrm{~Hz}$, and the flow diagram is shown in Figure 3.

In order to be able to evaluate the vibration intensity of 21 kinds of pavement test, vibrating test bench intensity of soft soil pavement, the weighted root mean square value statistical calculation of vibration acceleration signals is, respectively, selected. The equation for solving the root mean square value of acceleration $a_{w}$ is shown in the following equation $[24,27]$ :

$$
a_{w}=\left[\frac{1}{T} \int_{0}^{T} a_{w}^{2}(t) \mathrm{d} t\right]^{1 / 2},
$$

where $a_{w}(t)$ is the weighted acceleration time history function and $T$ is the duration of the measurement.

\subsubsection{Establishment of Effective Roughness Excitation Model.} In this paper, the test bench response is taken as the output to reverse the effective roughness of soft soil pavement. It mainly includes three parts: (1) establishing the vibration model of the vehicle-soft pavement system, obtaining the effective roughness model, and finding out the parameters that affect the effective roughness, including the stiffness and damping of the system and the displacement, speed, and acceleration of the wheel in the vertical direction. (2) Obtaining equivalent stiffness and equivalent damping by hammering experiment and modal parameter identification. (3) Carrying out one-time integration and two-time integration on the acceleration signal to obtain the vertical speed and displacement signals of the wheel.

(1) Effective Roughness Model. In the process of test, the wheels are set to be evenly and symmetrically excited by the ground, and the stiffness and damping of the soil itself would also affect the vibration characteristics of the vehicle. Therefore, the stiffness and damping of the vehicle-ground system are equivalently superimposed in the vertical direction $[22,27]$. The simplified process of the vibration system is shown in Figure 4.

Figure 4(a) is the actual vibration system model. Figure $4(\mathrm{~b})$ is the simplified vibration model. In the model, $K=k_{1}+k_{2}, C=c_{1}+c_{2} . q(t)$ is the effective ground roughness input excitation, and the vibration differential equation $[13,27]$ is established as shown in the following equation:

$$
m x \ddot{(} t)+C[x \dot{(t)}-q \dot{(t)}]+K[x(t)-q(t)]=0 .
$$

In the equation, $x(t)$ is the vertical vibration displacement of wheels; $x(t)$ is the vertical vibration speed of wheels; $x \ddot{x} t)$ is vertical vibration acceleration of wheels; $q(t)$ is the effective ground roughness input displacement.

The vertical displacement can be solved by

$$
\left.q(t)=x(t)+\frac{m}{K} x \ddot{(t}\right)+\frac{C}{K} x(t) .
$$

Here, the mass $m=103.5 \mathrm{~kg}$ and vehicle acceleration signal is $x \ddot{x} t)$. Measured by vibration test that, in order to be 


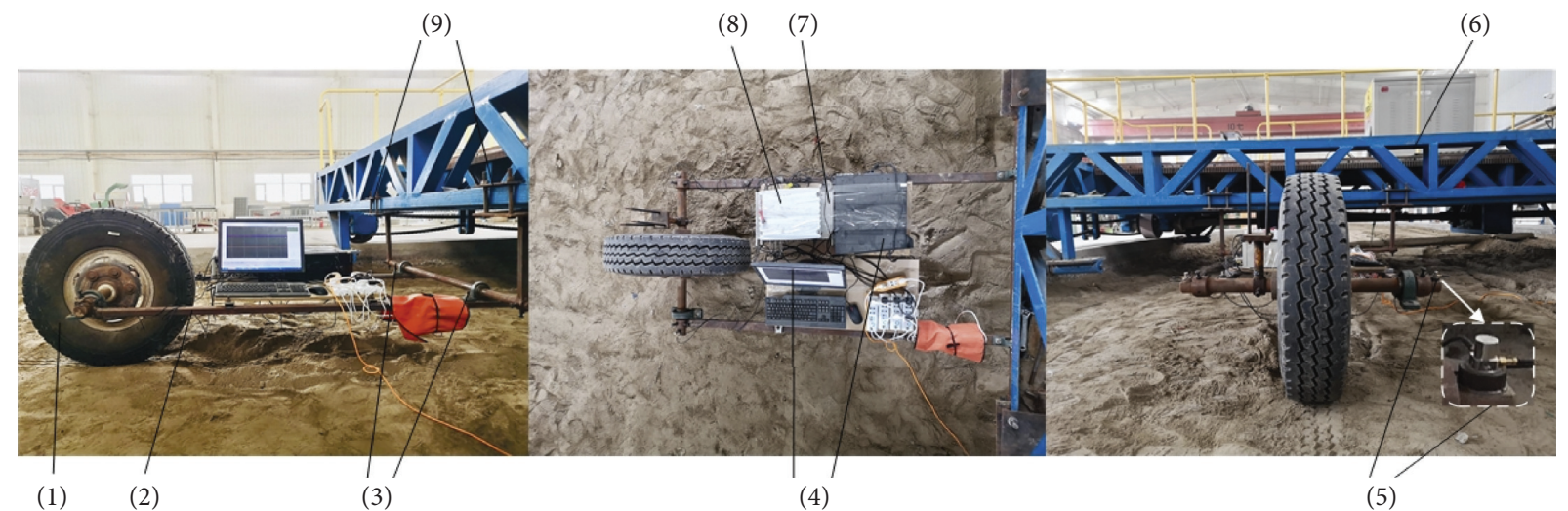

Figure 1: Test system. (1) Wheel assembly, (2) single wheel frame, (3) connection bearing, (4) computer, (5) acceleration sensor, (6) tractor, (7) signal amplifier, (8) data acquisition instrument, and (9) fixing device.

TABLE 1: Test statistics of solidarity (unit: $\mathrm{kg} / \mathrm{cm}^{2}$ ).

\begin{tabular}{|c|c|c|c|c|c|c|c|c|}
\hline \multirow{2}{*}{ Depth $(\mathrm{cm})$} & \multirow{2}{*}{ Columns } & \multicolumn{7}{|c|}{ Rows } \\
\hline & & 1 & 2 & 3 & 4 & 5 & 6 & 7 \\
\hline \multirow{3}{*}{10} & 1 & 10.2 & 13.8 & 12.6 & 12.4 & 13.7 & 13.8 & 8.8 \\
\hline & 2 & 15.8 & 12.6 & 14.7 & 13.8 & 14.8 & 15.9 & 16.2 \\
\hline & 3 & 14.6 & 9.2 & 10.7 & 12.5 & 10.4 & 11.3 & 10.6 \\
\hline \multirow{3}{*}{20} & 1 & 16.9 & 21.9 & 18.3 & 16.9 & 16.9 & 18.8 & 16.8 \\
\hline & 2 & 19.0 & 20.1 & 21.0 & 21.1 & 21.2 & 22.8 & 19.3 \\
\hline & 3 & 17.0 & 20.3 & 23.1 & 21.5 & 19.8 & 20.0 & 19.4 \\
\hline \multirow{3}{*}{30} & 1 & 38.2 & 32.5 & 30.1 & 29.7 & 30.1 & 36.5 & 47.0 \\
\hline & 2 & 41.7 & 50.7 & 38.8 & 32.0 & 23.1 & 33.9 & 39.2 \\
\hline & 3 & 37 & 36 & 33.1 & 21.5 & 29.8 & 20.9 & 29.4 \\
\hline
\end{tabular}

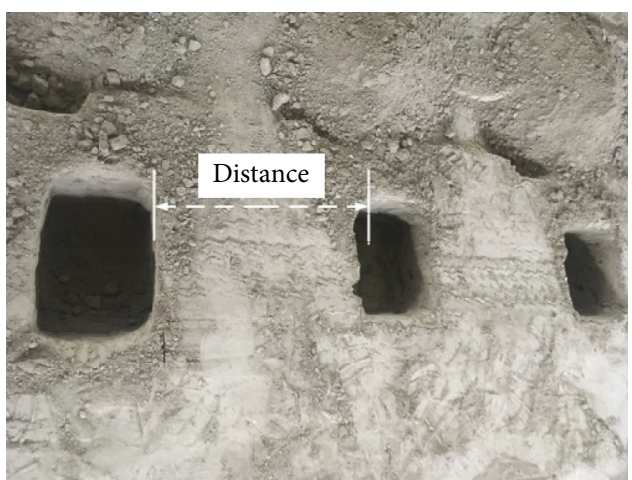

(a)

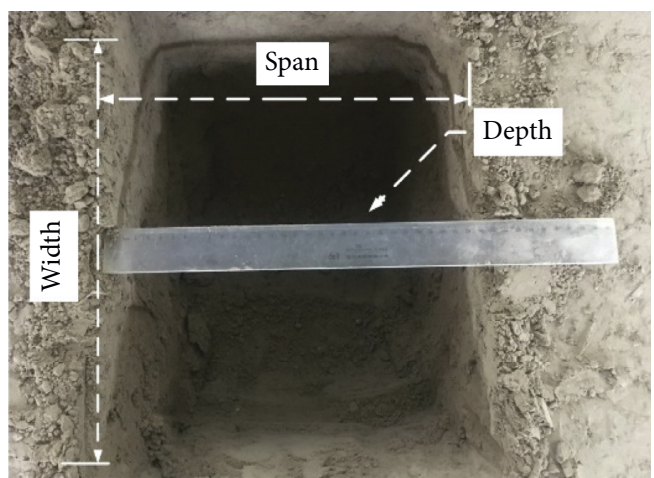

(b)

FIGURE 2: Sample of the rectangular pit.

able to evaluate the road excitation intensity of 21 kinds of pavement test, the power spectral density method of pavement effective roughness is, respectively, selected. The equation for solving the spectral density of effective roughness rate is shown in equation (4). Since the function curve of effective roughness is already known, the power spectral density [5] can be calculated by using a computer, as follows:

$$
P=\frac{1}{N} \sum_{k=0}^{N-1}[Q(k)]^{2} \text {. }
$$

Here, $P$ is the power spectral density of the effective roughness and $Q(k)$ is the spectral function of the effective roughness time domain signal $q(t)$ after Fourier transform, wherein, $k=1,2,3 \ldots$

(2) Test of Mechanical Parameters of Vehicle-Ground System. At present, the method of experimental modal analysis is relatively mature. Generally, it includes single-point excitation, multipoint excitation, and single-point partition excitation [28]. In this paper, the hammering method is used 


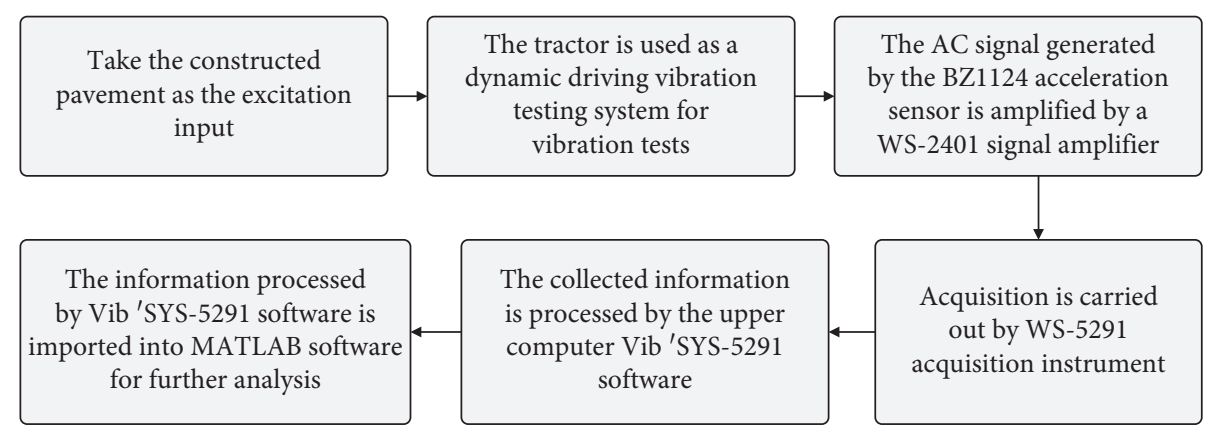

FIGURE 3: Vibration test flow.

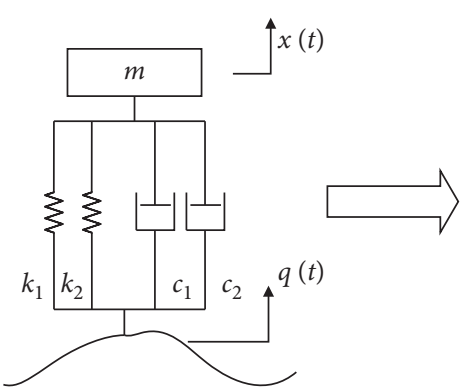

(a)

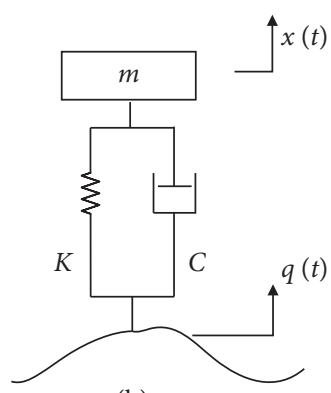

(b)

Figure 4: Simplified schematic diagram of the vehicle-ground system model. $k_{1}$ : soil vertical stiffness; $k_{2}$ : tire vertical stiffness; $c_{1}$ : soil vertical damping; $c_{2}$ : tire vertical damping; $x(t)$ : wheel up and down displacement; $q(t)$ : effective ground displacement input; $K$ : system vertical equivalent stiffness sum; $C$ : system vertical equivalent damping sum.

for testing, and the signal generated by hammering is taken as the excitation force signal and the signal measured by the acceleration sensor is taken as the response signal. The ratio of Laplace transform of the acceleration response signal to Laplace transform of the excitation signal is taken as system response, i.e., transfer function [29]. The transfer function signal curve is used to identify the parameters and obtain the mechanical parameters of the system. In this paper, a singlepoint hammer test method is selected. The force sensor model is LC-50 piezoelectric sensor (produced by Beijing Wavespectrum Science and Technology Co., Ltd.). The sampling frequency is $5000 \mathrm{~Hz}$, and the sampling time is 0.2 seconds, as shown in Figure 5.

After modal analysis, the natural frequency $\omega_{n}$, damping ratio $\xi$, equivalent stiffness $K$, and equivalent damping $C$ of the system can be obtained.

The relationship between each parameter is shown in equations 6 and (7) [27, 29]:

$$
\begin{aligned}
\omega_{n}^{2} & =\frac{K}{m}, \\
\xi & =\frac{C}{2 m \omega_{n}} .
\end{aligned}
$$

In order to obtain the wheel vertical displacement signal $x(t)$ and the wheel vertical speed signal $x(t)$, it is necessary to carry out one-time integration and two-time integration on the measured wheel vertical acceleration signal $x \ddot{(} t)$. For signal integration, there are mainly two methods: time domain integration and frequency domain integration. As time domain integration will cause the generation of DC component and trend term of signal, it will lead to integration error, while frequency domain integration can convert integration operation into division operation, which can better avoid the generation of error $[29,30]$. As a result, the frequency domain primary integration of the acceleration signal is performed to obtain the frequency spectrum of the velocity signal as follows:

$$
V(K)=\frac{A(K)}{j \omega} \sum_{n=0}^{N} \frac{1}{j 2 \pi k \Delta f} H(K) a_{n} e^{-j 2 \pi k n / N} .
$$

The frequency spectrum of the displacement signal obtained by quadratic integration is

$$
S(K)=\frac{A(K)}{\omega_{k}^{2}} \sum_{n=0}^{N} \frac{1}{(2 \pi k \Delta f)^{2}} H(K) a_{n} e^{-j 2 \pi k n / N} .
$$

Here,

$$
H(K)= \begin{cases}1, & f_{d}<k \Delta f<f_{u} \\ 0, & \text { otherwise }\end{cases}
$$

where $\Delta f$ is frequency resolution; $f_{d}$ is the lower limit of the cutoff frequency; $f_{u}$ is the upper limit of cutoff frequency; $N$ is the number of sampling points of the data; and $\omega_{k}$ is the frequency corresponding to the Fourier component.

\section{Vibration Test Analysis}

The acceleration signal in the vertical direction of the wheel is collected through the vibration test system, and the collected voltage signal value is imported into the $m$ file written by MATLAB and converted into the acceleration signal value. The vibration response data of 21 kinds of pavements are divided into 7 groups by span, and each group contains pavement data of 3 different depths for comparison and display, as shown in Figure 6. It can be seen that each group of data can see 10 peaks, proving that each rectangular pit constructed can cause vehicle vibration.

MATLAB is used to write a program to calculate the power spectral density of the signal, as shown in Figure 7. It can be seen that the frequency band range in the power 


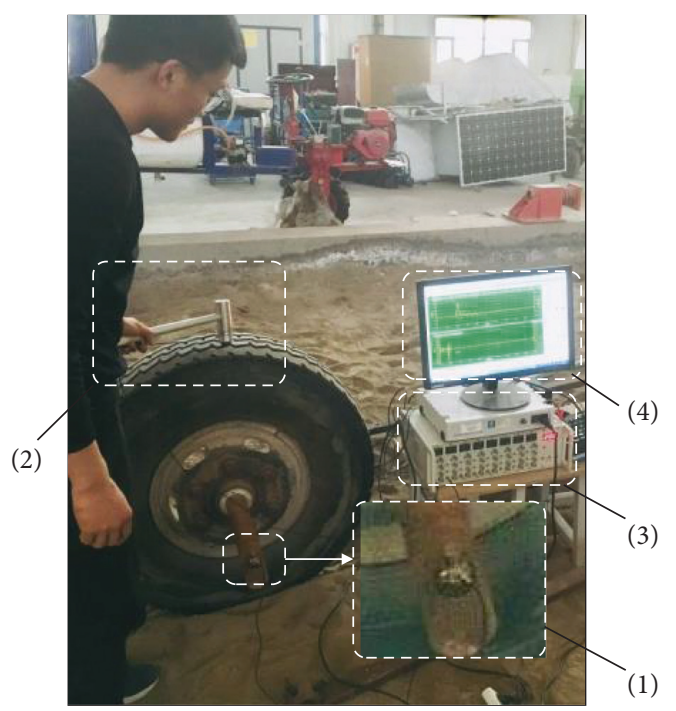

FIGURE 5: Schematic diagram of hammering test. (1) Acceleration sensor; (2) force hammer sensor; (3) signal amplification and acquisition equipment; (4) computer display.

spectral density is $0 \sim 13 \mathrm{~Hz}$, and the most active part of the vibration power value is $0 \sim 3 \mathrm{~Hz}$. It is close to the test frequency band of tractor vibration in references [21, 24, 31-33], and the frequency band range does not change significantly with the change of rectangular pit size. This shows that, under the excitation of soft soil pavement, the vehicle vibration is mainly in the low-frequency range, and the SDOF vibration test system can reflect the overall vibration characteristics of the tractor. The vibration response signal is analyzed within $0 \sim 3 \mathrm{~Hz}$, and four peak points appear. Taking the data with a span of $10 \mathrm{~cm}$ and three different depths as an example, the data rules are consistent.

3.1. Effective Roughness Model Parameters. The transfer function of the vehicle-ground system is obtained through hammering test, as shown in Figure 8. Both the real part and the imaginary part of the transfer function curve have 5 peak points. The first-order natural frequency $[28,29]$ is obtained by selecting the peak frequency with the real part being 0 and the imaginary part being the highest and carrying out modal parameter identification. A total of 7 hammering tests were carried out (test has the same law for 7 times), and the 7 test data of the first-order natural frequency were averaged. The results are shown in Table 2.

The first-order natural frequency is selected as the dominant frequency of the system, and the $\omega_{n}$ value is $211.8998 \mathrm{~Hz}$. Modal parameters of the first-order natural frequency are identified to obtain damping ratio $\xi=1.16 \%$. Combining equations 6 and (7), the vertical equivalent stiffness $K$ is $4647307.86 \mathrm{~N} \mathrm{~m}^{-1}$ and the equivalent damping coefficient $C$ is $508.8138 \mathrm{~N} \mathrm{~s} \mathrm{~m}^{-1}$.

3.2. Vertical Wheel Displacement and Speed Signals. The frequency domain integration program is written by MATLAB, and the vertical vibration acceleration signal of the axle is integrated first and second in the frequency domain. The upper and lower limit cutoff frequencies are $100 \mathrm{~Hz}$ and $0.3 \mathrm{~Hz}$ [34], respectively, and the vertical speed signal $x(t)$ and displacement signal $x(t)$ of the axle are obtained, as shown in Figure 7 (the data are data with a depth of $10 \mathrm{~cm}$ and a span of $10 \mathrm{~cm}$ ). Combining equations 8 and (9), it can be seen that frequency domain integration is equivalent to division operation in frequency domain, so the amplitude would be amplified when the frequency is in the range of $0 \sim 1 \mathrm{~Hz}$, and the amplitude would decrease when it is greater than $1 \mathrm{~Hz}$, and the amplitude would increase and decrease as the frequency value increases. As a result, the signal shows a smooth trend in the time domain with the increase of the number of frequency domain integrations, as shown in Figure 9(a). As the number of frequency domain integrations increases in the frequency domain, the amplitude of the signal gradually increases in the lower frequency range and gradually decreases in the higher frequency range, as shown in Figure 9(b).

3.3. Effective Roughness Signal. The vertical speed signal $\dot{x}(t)$ and displacement signal $x(t)$ of the axle, as well as the stiffness $K$ and damping $C$ are obtained, and the time domain signal of the effective roughness is obtained by solving equation (4). Since the effective roughness of soft soil pavement is the superposition of the vertical displacement and velocity of test bench and the product of acceleration and various mechanical parameters, as well as the value of vertical stiffness $K$ is much larger than the value of vertical damping $C$ and vertical mass $m$, the product of speed and acceleration and various mechanical parameters is smaller, and the sum of tire deformation is smaller, due to relatively small stiffness of soil compared to tire. So, the effective roughness value basically depends on the vertical displacement of the wheel. As shown in Figure 10, the span is $10 \mathrm{~cm}$. The data of rectangular pit pavement with depths of $10 \mathrm{~cm}, 20 \mathrm{~cm}$, and $30 \mathrm{~cm}$ show that the amplitude of effective roughness changes irregularly with the increase of depth. The rest of the data are consistent with the above. Fourier transform is performed on the effective roughness time domain signal to obtain a frequency domain diagram. As shown in Figure 10(b), the excitation frequency band range is from 0 to $3 \mathrm{~Hz}$, and that frequency values corresponding to the two peak points of each group of data are different. The resulting difference has a linear multiple relationship with the frequency corresponding to the first peak point. The vertical displacement of the peak point decreases with the increase of frequency, which is similar to the nonsinusoidal periodic signal [35]. The rest of the data are consistent with the above.

\section{Discussion}

4.1. Correlation Analysis of Effective Roughness, Original Road Roughness, and Main Frequency Band of Vibration Response. This experiment includes 21 kinds of rectangular pit pavements with 7 different wavelengths. Because the constructed rectangular pit pavement is similar to a nonsinusoidal periodic signal, there will be frequency doubling. Since there are 4 peak 


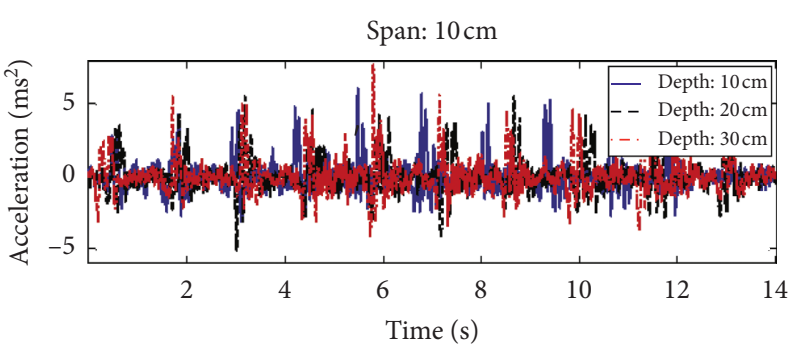

(a)

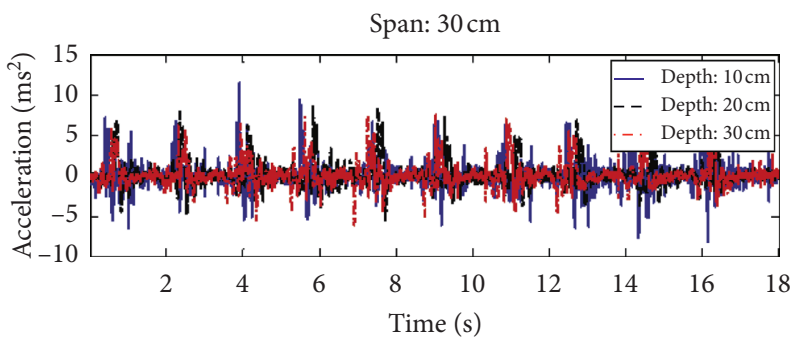

(c)

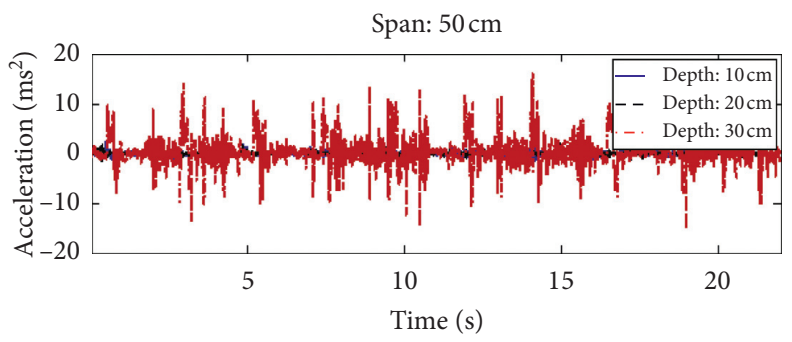

(e)

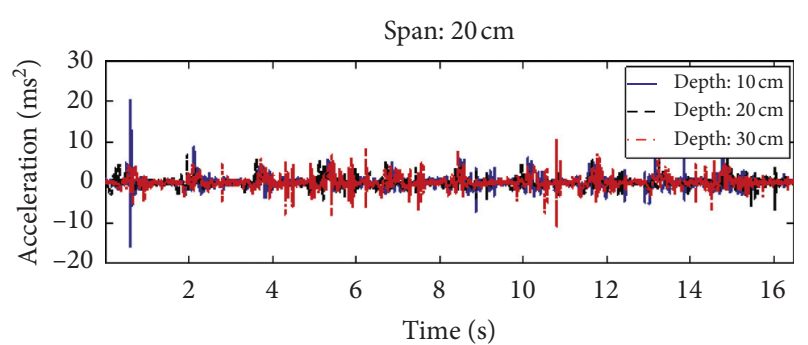

(b)

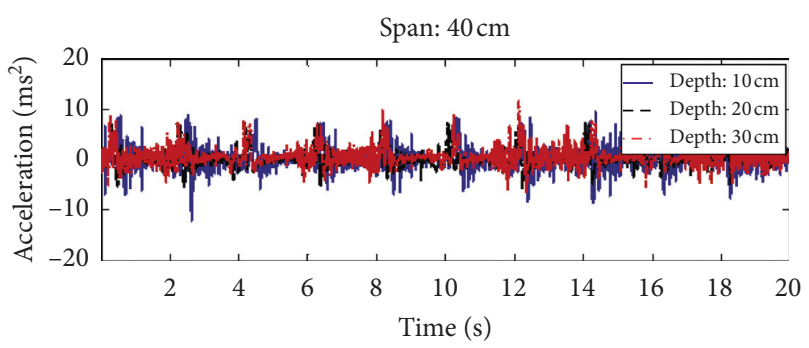

(d)

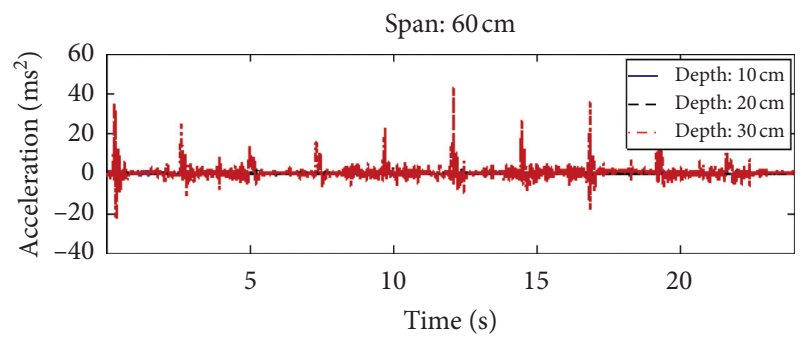

(f)

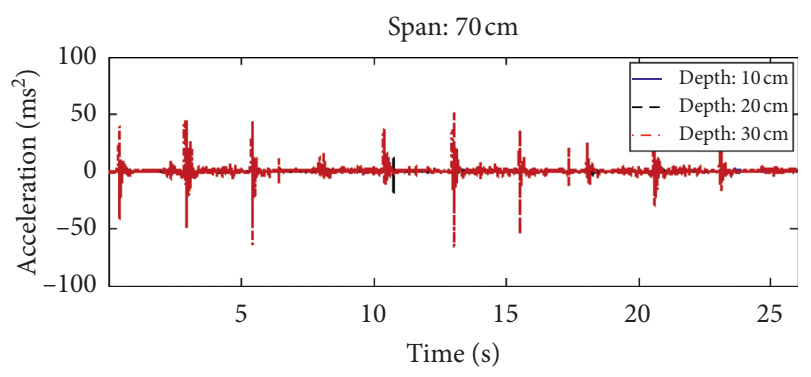

(g)

FIgURE 6: Time-domain diagram of the vibration acceleration signal.

points in the spectrum diagram of the effective roughness signal, the four frequency doubles of the original road roughness excitation signal are counted, and Table 3 is drawn in combination with the spatial frequency $n$ and time frequency $f$ corresponding to different wavelengths, as follows.

Linear regression analysis is carried out on the peak point frequency of the effective roughness model signal, the excitation point frequency of the original pavement roughness, and the four peak point frequencies of the main frequency band of the vibration signal, respectively. The results show that the coefficients of the linear regression equation between the effective roughness model signal and the excitation point frequency of the original pavement roughness are close to 1 , and the $R^{2}$ value ranges from 0.9641 to
0.9969. The coefficients of the frequency linear regression equation of the four peak points of the main frequency band of the effective roughness model signal and the vibration acceleration signal are all around 1 , and the $R^{2}$ value range is 0.992165 1, as shown in Table 4. It is shown that the effective irregularity excitation frequency is highly correlated with the original irregularity excitation point frequency of rectangular pit pavement. The feasibility of the effective roughness solution method is verified. It is proved that the excitation point of the vehicle when driving on the soft road surface is the rear end of the rectangular pit. At the same time, it is shown that the main frequency band of vehicle vibration is highly correlated with the excitation signal of the road surface and basically depends on the excitation characteristics of the ground. 


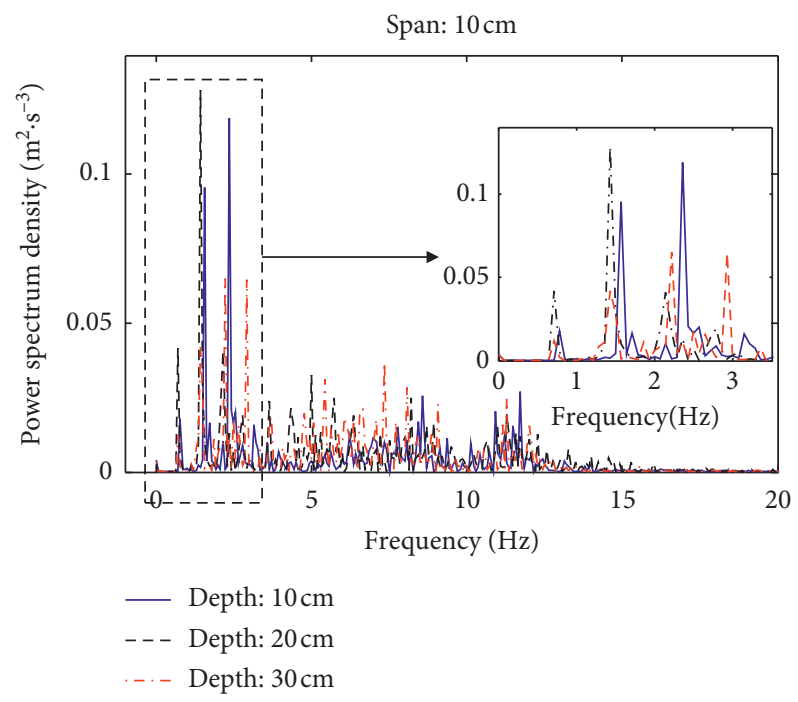

Figure 7: Frequency domain diagram of the vibration acceleration signal.

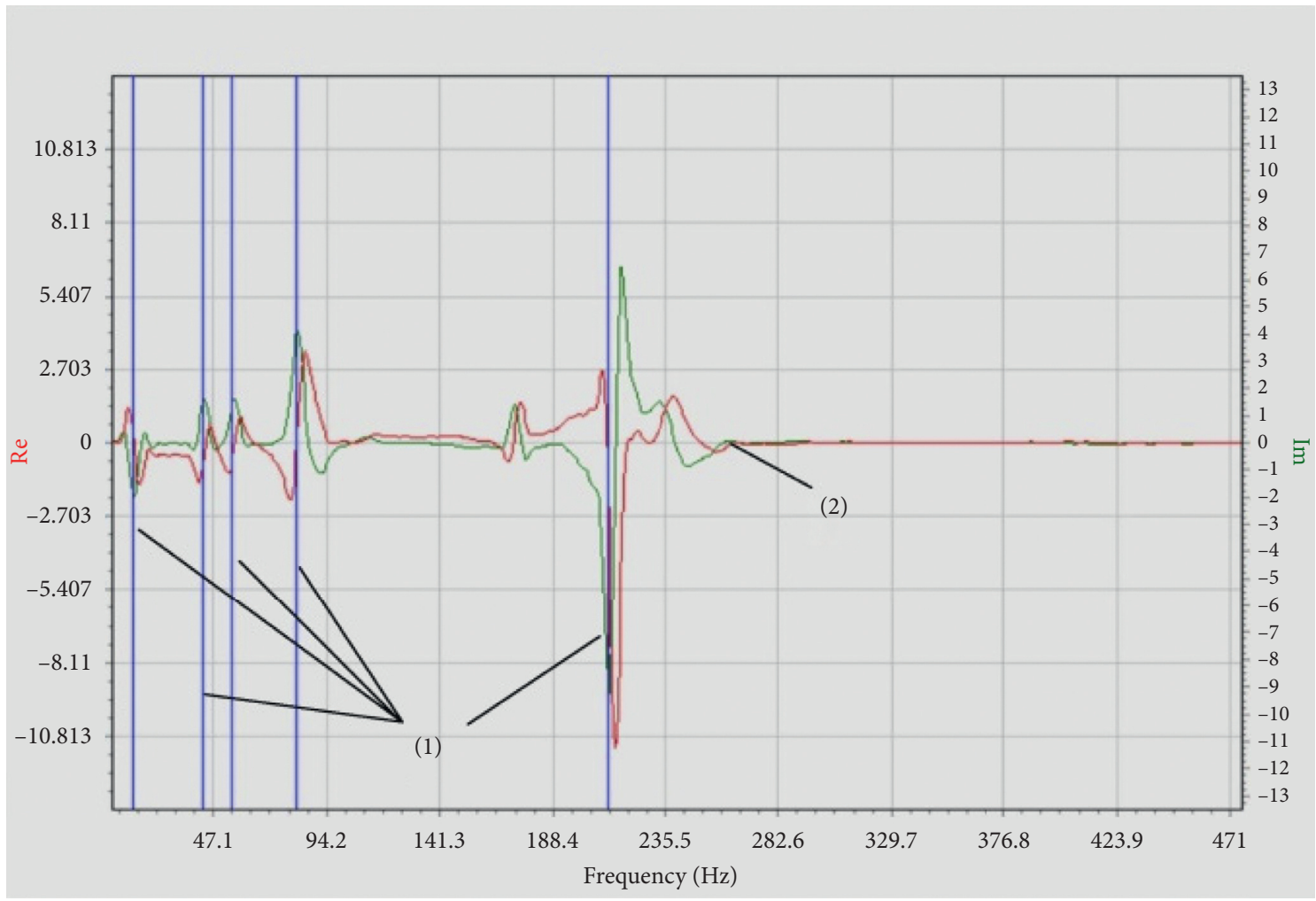

Figure 8: Hammer test: (1) 5-order mode shape; (2) transfer function curve.

TABle 2: Statistics of first-order natural frequency of the vehicleground system (unit: $\mathrm{Hz}$ ).

\begin{tabular}{lcc}
\hline Number of hammers & First order natural frequency & Average \\
\hline 1 & 211.128 & \\
2 & 211.792 & \\
3 & 212.235 & 211.8998 \\
4 & 211.885 & \\
5 & 212.127 & \\
6 & 211.787 & \\
7 & 211.838 & \\
\hline
\end{tabular}

Linear fitting is carried out on the frequency value of the original road roughness excitation, and the actual measured peak frequencies of the effective roughness are compared with the four peak frequencies of the main frequency band of the vibration signal, as shown in Figure 11. It can be seen that the difference between the three is small, and with the change of rectangular pit depth, the excitation frequency and vibration frequency values do not change significantly. With the increase of the rectangular pit span, the excitation frequency and vibration frequency values decrease. This shows 

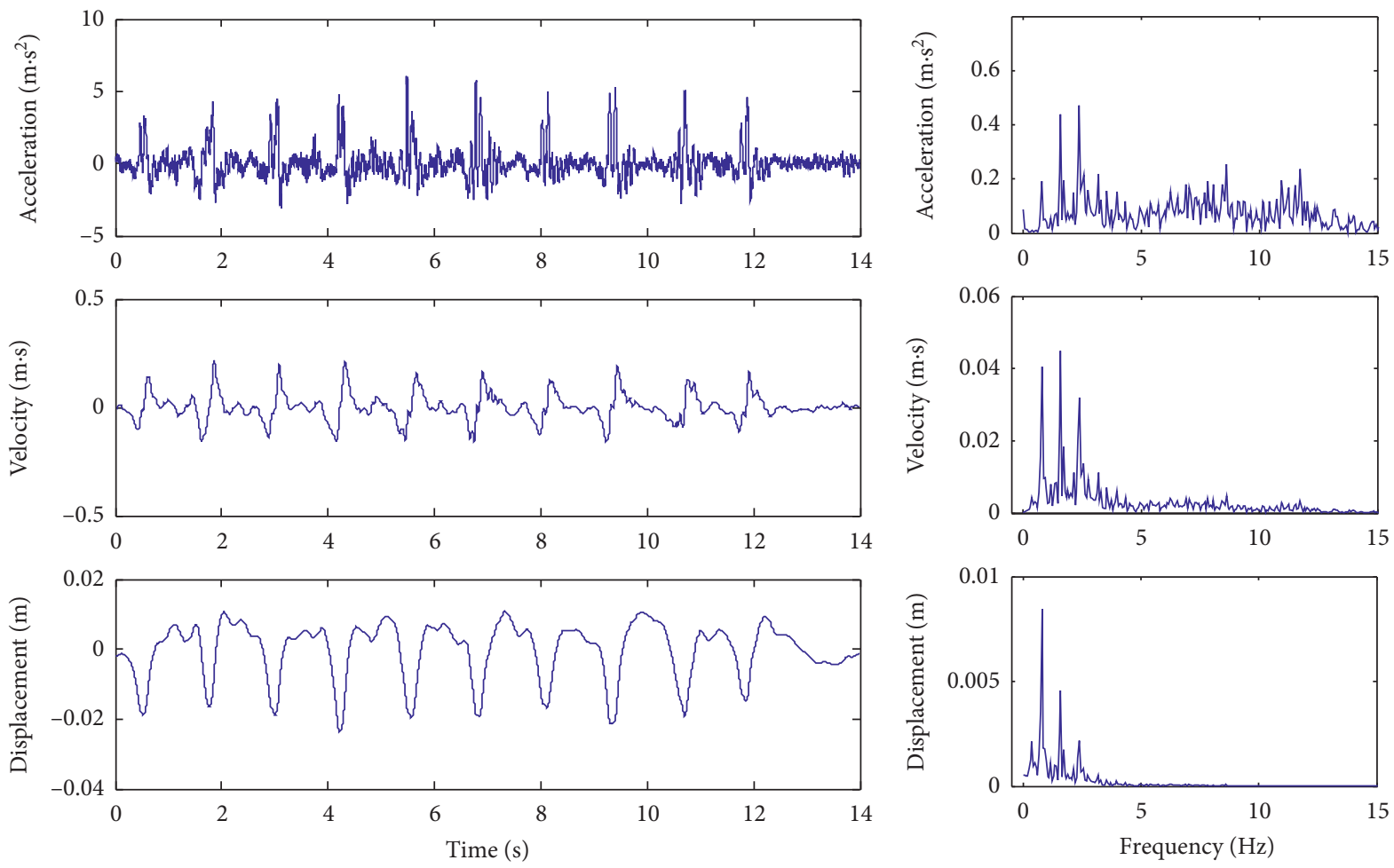

(a)

(b)

FIgURE 9: Primary and secondary frequency domain integration and time and frequency correspondence diagram of vibration acceleration signal. (a) Time domain diagram. (b) Frequency domain diagram.

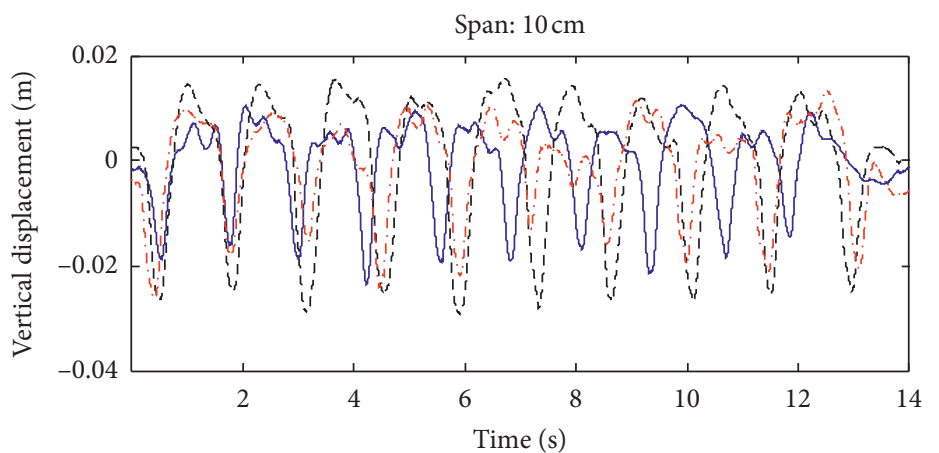

_ Depth: $10 \mathrm{~cm}$
- - Depth: $20 \mathrm{~cm}$
-.- Depth: $30 \mathrm{~cm}$

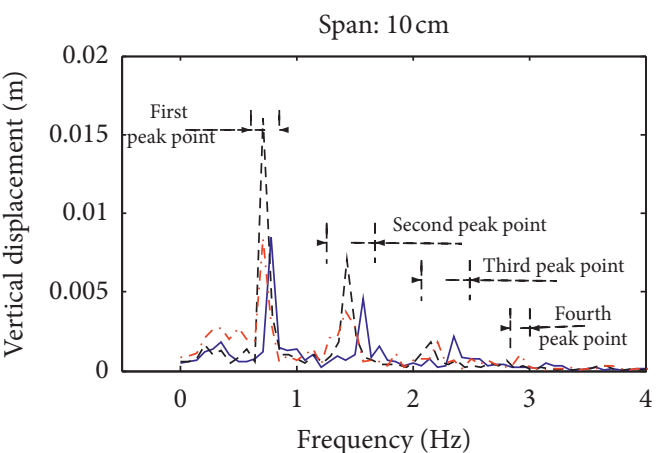

— Depth: $10 \mathrm{~cm}$

- - Depth: $20 \mathrm{~cm}$

$\rightarrow$ - Depth: $30 \mathrm{~cm}$

(b)

Figure 10: Time-frequency correspondence diagram of effective roughness. (a) Time domain diagram. (b) Frequency domain diagram.

that the change of rectangular pit span is the main reason to change the road wavelength, indirectly changing the excitation frequency of effective uneven and vibration frequency value of vehicles. At the same time, the frequency of effective roughness excitation points is slightly lower than that of the original pavement excitation points. There are mainly two reasons: (1) systematic errors will occur when the application of measuring tools and shovels cannot be completely unified when the road surface is constructed manually. (2) In the process of test, tires and soil will deform and increase the wavelength of the original road surface, resulting in the effective roughness excitation frequency (consistent with the vibration frequency) being smaller than the original road surface roughness excitation frequency value.

4.2. Correlation Analysis of Vibration Acceleration Intensity and Effective Roughness Intensity. MATLAB combination equation (2) is used to solve and make statistics on the root mean square value of acceleration of 21 kinds of road surface 
TABLE 3: Statistics of calculation results of excitation point wavelength, spatial frequency, and quadruple frequency of original pavement roughness signal.

\begin{tabular}{|c|c|c|c|c|c|c|}
\hline \multirow{2}{*}{ Span (unit: $\mathrm{cm}$ ) } & \multirow{2}{*}{ Wavelength, $\lambda$ (unit: $\mathrm{m}$ ) } & \multirow{2}{*}{ Spatial frequency, $n$ (unit: $\mathrm{m}^{-1}$ ) } & \multicolumn{4}{|c|}{ Quadruple frequency time frequency (unit: $\mathrm{Hz}$ ) } \\
\hline & & & Fundamental & Double & Triple & Quadruple \\
\hline 10 & 0.7 & 1.429 & 0.794 & 1.588 & 2.382 & 3.176 \\
\hline 20 & 0.8 & 1.250 & 0.694 & 1.388 & 2.082 & 2.776 \\
\hline 30 & 0.9 & 1.111 & 0.617 & 1.234 & 1.851 & 2.464 \\
\hline 40 & 1.0 & 1.000 & 0.556 & 1.112 & 1.668 & 2.224 \\
\hline 50 & 1.1 & 0.909 & 0.505 & 1.010 & 1.515 & 2.020 \\
\hline 60 & 1.2 & 0.833 & 0.463 & 0.928 & 1.391 & 1.854 \\
\hline 70 & 1.3 & 0.769 & 0.427 & 0.854 & 1.281 & 1.708 \\
\hline
\end{tabular}

TABLE 4: Regression analysis of effective roughness peak point frequency and original roughness excitation point and vibration signal main frequency band peak point frequency.

\begin{tabular}{|c|c|c|c|c|c|c|c|}
\hline \multirow[t]{2}{*}{ Depth $(\mathrm{cm})$} & \multirow[t]{2}{*}{ Peak point } & \multicolumn{3}{|c|}{$\begin{array}{l}\text { Frequency regression analysis of effective } \\
\text { roughness and original roughness }\end{array}$} & \multicolumn{3}{|c|}{$\begin{array}{l}\text { Regression analysis of effective roughness and } \\
\text { main frequency band of vibration signal }\end{array}$} \\
\hline & & Regression equation & Standard error & $R^{2}$ & Regression equation & Standard error & $R^{2}$ \\
\hline \multirow{4}{*}{10} & First peak point & $y=1.0009 x-0.0482$ & 0.027790 & 0.964080 & $y=0.9730 x+0.0174$ & 0.012979 & 0.992165 \\
\hline & Second peak point & $y=1.0619 x-0.1499$ & 0.034771 & 0.987183 & $y=0.9772 x+0.0309$ & 0.007792 & 0.999356 \\
\hline & Third peak point & $y=1.0736 x-0.2628$ & 0.057738 & 0.983743 & $y=0.9639 x+0.0704$ & 0.025687 & 0.996959 \\
\hline & Fourth peak point & $y=0.8164 x+0.1873$ & 0.095525 & 0.976495 & $y=1.0134 x-0.0394$ & 0.034624 & 0.996912 \\
\hline \multirow{4}{*}{20} & First peak point & $y=0.8768 x+0.0110$ & 0.007053 & 0.996882 & $y=x$ & 0 & 1 \\
\hline & Second peak point & $y=0.8730 x+0.0407$ & 0.032586 & 0.983410 & $y=0.9867 x+0.0124$ & 0.003107 & 0.999849 \\
\hline & Third peak point & $y=0.9124 x-0.0119$ & & 0.992006 & $y=0.9872 x+0.0177$ & 0.004976 & 0.999841 \\
\hline & Fourth peak point & $y=0.6540 x+0.5266$ & 0.047584 & 0.991348 & $y=0.9846 x+0.0364$ & 0.02293 & 0.997991 \\
\hline \multirow{4}{*}{30} & First peak point & $y=0.8768 x+0.0110$ & 0.007053 & 0.996882 & $y=x$ & 0 & 1 \\
\hline & Second peak point & $y=0.9117 x-0.0033$ & 0.036182 & 0.981283 & $y=x$ & 0 & 1 \\
\hline & Third peak point & $y=0.9431 x-0.0654$ & 0.035183 & 0.992572 & $y=x$ & 0 & 1 \\
\hline & Fourth peak point & $y=0.7153 x+0.3941$ & 0.035697 & 0.995736 & $y=x$ & 0 & 1 \\
\hline
\end{tabular}

data, as shown in Figure 11(a). Combined with equation (5), the effective irregularity power spectral density value is solved and counted, as shown in Figure 11(b). It can be seen from the test data of 7 spans with a depth of $30 \mathrm{~cm}$ and the depth of 10 20 cm and the span of 10 40 cm that, with the increase of the span, the weighted root mean square value of vibration acceleration and the power spectral density value of effective roughness of road surface increase. This is due to the increase of rectangular pit size, which leads to the increase of wheel vertical displacement and effective roughness power value. At the same time, the vertical displacement of the wheels increases, which results in an increase in the shear force given to the wheels by the soil [6]. As a result, an increase in the vertical moving load on the vibration test bench occurs when driving on the road [34], so the instantaneous excitation suffered by the wheels when passing through the rear end of the rectangular pit increases, thus enhancing the vibration intensity of the vehicle. As shown in Figure 12(b), with this increase of the depth of the rectangular pit, the amount of subsidence at the front and rear end of the rectangular pit increases, so that the effective roughness power spectral density value increases accordingly. However, with the increase of the depth of the rectangular pit, the weighted root mean square value of the vibration acceleration signal does not change significantly, as shown in Figure 12(a). It is mainly because the effective roughness is basically equal to the vertical displacement of the wheel, and it shows that the acceleration signal is mainly noise at $4 \sim 13 \mathrm{~Hz}$ since the amplitude of the acceleration signal and the effective roughness signal are mainly concentrated in $0 \sim 3 \mathrm{~Hz}$, as well as the coupling between the vibration acceleration signal frequency and the effective roughness excitation frequency. Therefore, there are errors in the acceleration signal measured by the vibration testing system, resulting in irregular changes in the root mean square value of the acceleration signal with the increase of the depth of the road rectangular pit. At the same time, two integrals are carried out in the process of solving the effective roughness, which will reduce the noise part and improve the prediction accuracy of the effective roughness of soft pavement. Therefore, with the increase of the depth of rectangular pit, the power spectral density value of the effective roughness increases obviously. When the depth is $10 \sim 20 \mathrm{~cm}$ and the span is $50 \mathrm{~cm}, 60 \mathrm{~cm}$, and $70 \mathrm{~cm}$, the vibration amplitude is small because the wheel collapses too fast when passing through the front end of the rectangular pit. In the meantime, the wheel will contact the bottom of the rectangular pit, the collapsed soft soil will fall on the bottom of the rectangular pit as a buffer, and the rear end of the rectangular pit cannot directly give excitation, resulting in the process which cannot generate large excitation. It shows that, in the complete excitation of the rectangular pit (in this paper, the test data of 7 spans with a depth of $30 \mathrm{~cm}$ and the test data with a depth of $10 \sim 20 \mathrm{~cm}$ 


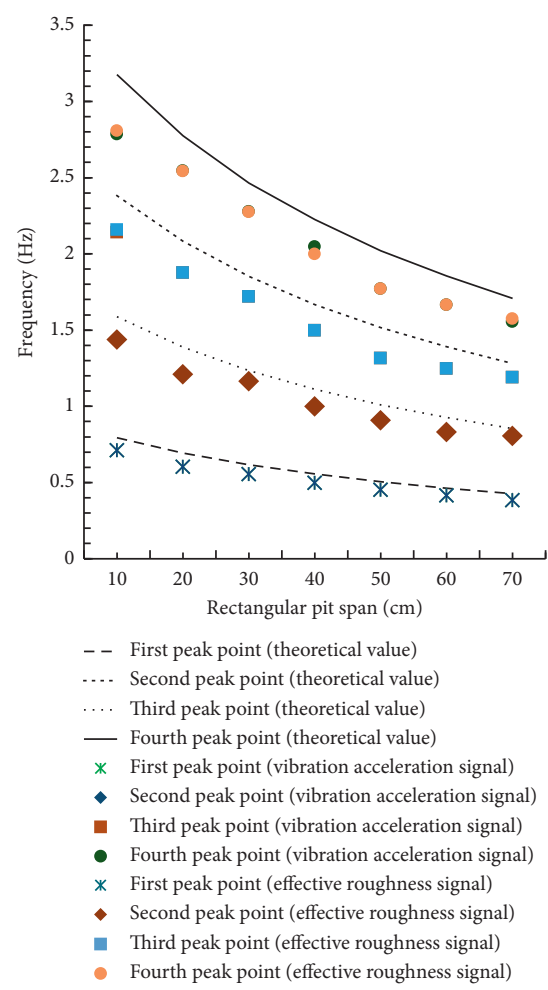

(a)

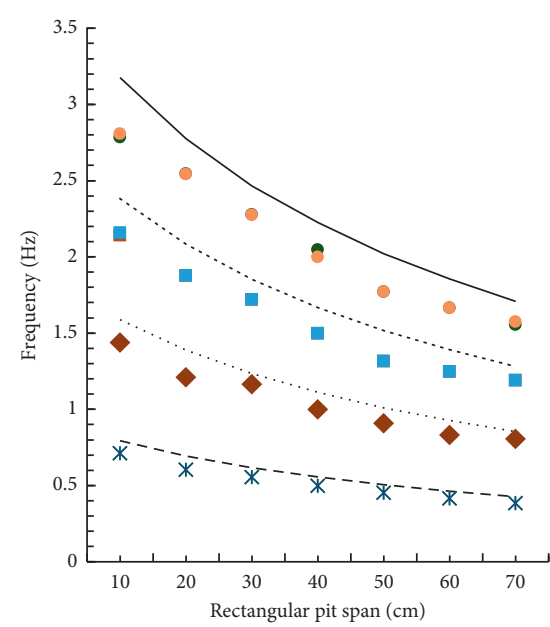

- - First peak point (theoretical value)

.... Second peak point (theoretical value)

. Third peak point (theoretical value)

— Fourth peak point (theoretical value)

* First peak point (vibration acceleration signal)

- Second peak point (vibration acceleration signal)

- Third peak point (vibration acceleration signal)

- Fourth peak point (vibration acceleration signal)

* First peak point (effective roughness signal)

- Second peak point (effective roughness signal)

- Third peak point (effective roughness signal)

- Fourth peak point (effective roughness signal)

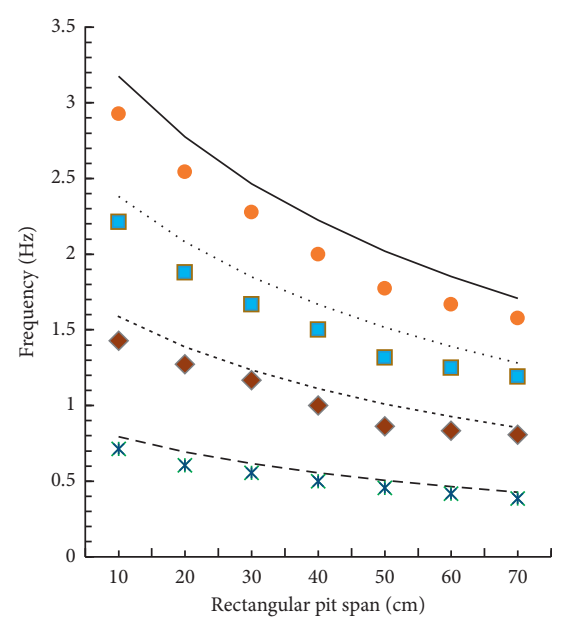

- - First peak point (theoretical value)

... Second peak point (theoretical value)

Third peak point (theoretical value)

— Fourth peak point (theoretical value)

* First peak point (vibration acceleration signal)

- Second peak point (vibration acceleration signal)

- Third peak point (vibration acceleration signal)

- Fourth peak point (vibration acceleration signal)

* First peak point (effective roughness signal)

- Second peak point (effective roughness signal)

- Third peak point (effective roughness signal)

- Fourth peak point (effective roughness signal)

(c)

FIgURE 11: Comparison of the frequency value of original road roughness excitation point, frequency value of effective roughness peak point, and frequency value of vibration peak point. (a) Depth: $10 \mathrm{~cm}$. (b) Depth: $20 \mathrm{~cm}$. (c) Depth: $30 \mathrm{~cm}$.

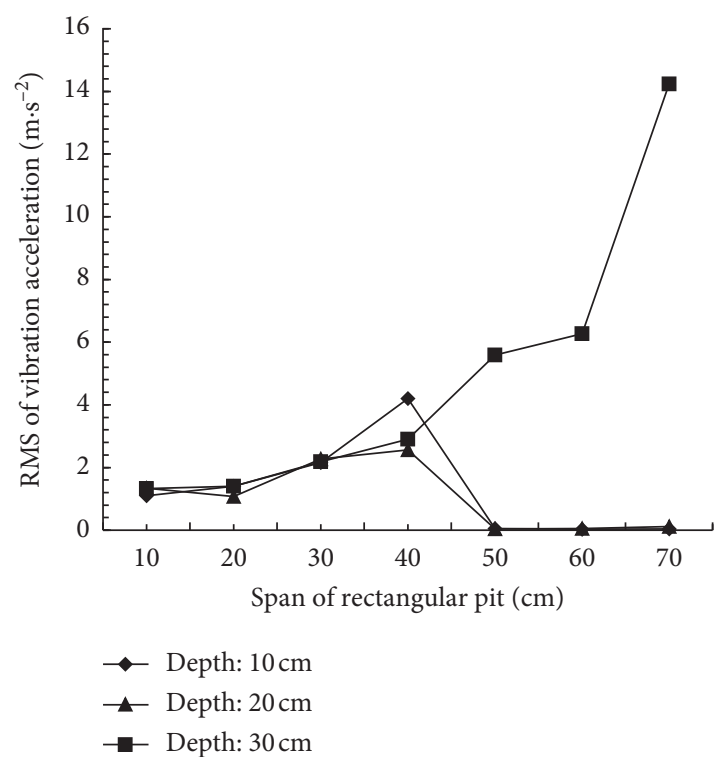

(a)

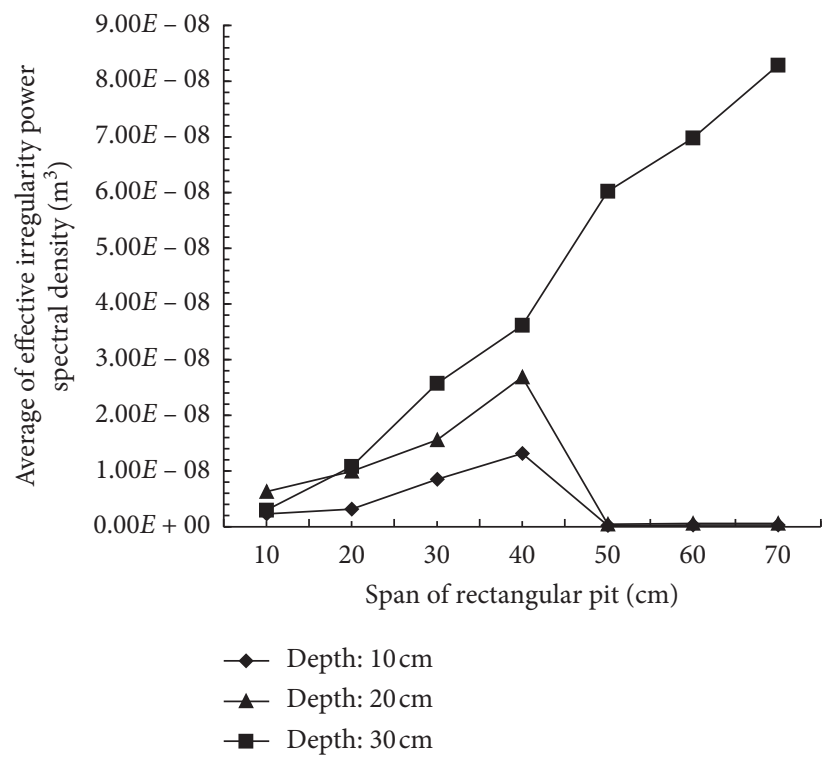

(b)

FIGURE 12: Vibration response and road excitation law. (a) RMS of vibration acceleration, (b) Average of effective irregularity power spectral density.

and a span of $10 \sim 40 \mathrm{~cm}$ are called complete excitation of rectangular pit, and the rest data are called incomplete excitation of rectangular pit), the increase of rectangular pit span is the main reason for the increase of vehicle vibration power.
We continue to carry out statistical analysis on the vertical displacement corresponding to the four peak points of the power value of the four peak points of the first band of the vibration signal and the four peak points of the effective roughness. Figure 13 is a rectangular pit road surface with a 


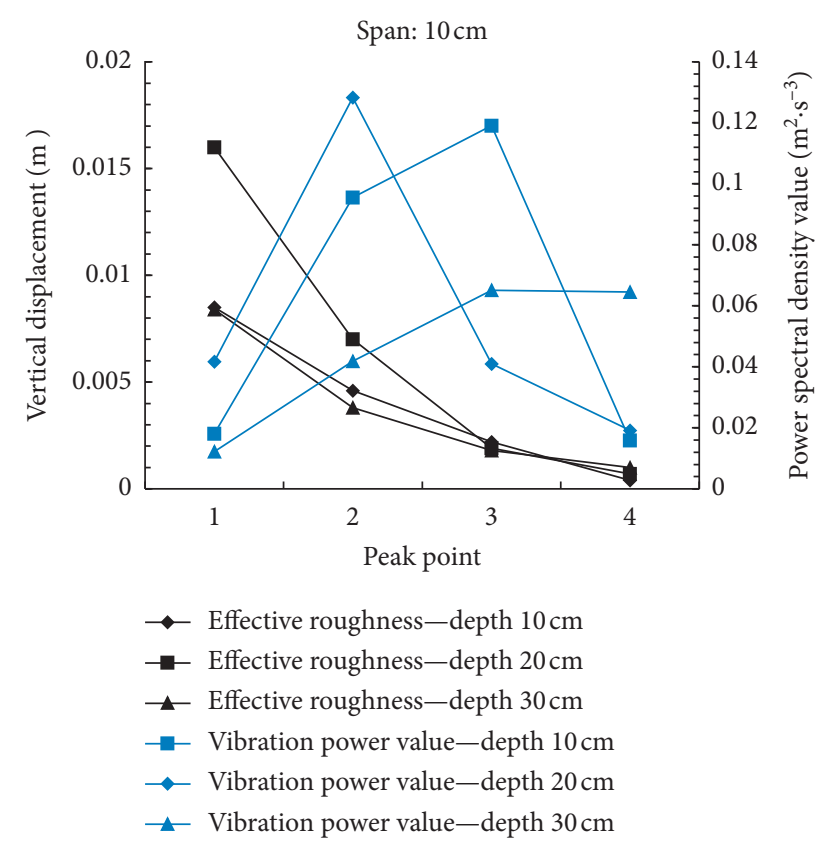

FIGURE 13: Vertical displacement of vibration power value and effective roughness corresponding to peak point.

span of $10 \mathrm{~cm}$ and a depth of $10 \mathrm{~cm}, 20 \mathrm{~cm}$, and $30 \mathrm{~cm}$. It can be seen that, with the increase of the peak point, the vibration power value increases first and then decreases. The highest peak is the second peak point and the third peak point. The vertical displacement of the effective roughness excitation point decreases in turn. The maximum value is at the first peak point, which conforms to the excitation law of the constructed pavement, and the other data laws are consistent. The main reason is that the effective irregularity excitation characteristics mainly depend on the vertical displacement of the wheel, and the first peak point is amplified in turn and the other peak points are reduced in turn in the two integration processes. It shows that the double frequency and triple frequency of road excitation are the main frequencies that cause the maximum vibration power of vehicles. Moreover, in the frequency domain, the output signal is the product of the frequency response function of the system and the input signal [29], indicating that the frequency response function of the system is the most active in the excitation of frequency doubling 2 and frequency doubling 3. At the same time, the vibration generated by the ground excitation of the whole tractor is in the low frequency band $(0 \sim 3 \mathrm{~Hz})[21,24,31-33]$. When the acceleration signal is integrated in the frequency domain, the signal in the $0 \sim 1 \mathrm{~Hz}$ frequency band would be amplified, and the signal in the $1 \sim 3 \mathrm{~Hz}$ frequency band would be reduced, which results that the soil soft road excitation corresponding to the highest peak of the vehicle vibration response is not the fundamental frequency. At the same time, it provides a reference for the prediction of soft soil pavement excitation and the design of tractor vibration reduction.

\section{Conclusions}

In this paper, the constructed rectangular pit pavement is used to simulate the field soft pavement with different wavelengths, and the test is carried out in combination with the vibration test system. The effective roughness model is established through the vibration equation of the vehicleground system, and the effective roughness of soft pavement is obtained, which is used as the excitation characteristic of pavement. In order to explore the correlation between the excitation characteristics of different long-wave roads in the field and the vibration response of vehicles, the following conclusions are drawn.

(1) In the full excitation of the rectangular pit, the increase of the span of the rectangular pit leads to the increase of the effective irregularity excitation wavelength and the decrease of the excitation frequency given to the wheel. At the same time, the increase of rectangular pit span leads to the increase of vertical moving load during the driving process of the vehicle, resulting in the increase of vehicle vibration intensity. In the incomplete excitation of the rectangular pit, the collapse of the front end of the rectangular pit will form a buffer zone. The wheel cannot directly contact the rear end of the rectangular pit due to the contact with the bottom of the rectangular pit, which is difficult to cause large excitation.

(2) The correlation coefficient $\left(R^{2}\right)$ between the frequency of the peak point of effective roughness and the frequency of the excitation point at the back end of the rectangular pit is 0.9641 0.9969, and the frequency range is $0 \sim 3 \mathrm{~Hz}$. This shows the effectiveness of the method for solving the effective roughness of soft soil pavement and determines the rear end of rectangular pit as the main excitation point. The correlation coefficient $\left(R^{2}\right)$ between the main frequency band frequency of the vibration test bench response acceleration signal and the effective roughness excitation frequency ranges from 0.992165 to 1 . It indicates that the vibration frequency generated by agricultural vehicles traveling on soft pavement is mainly determined by the excitation frequency of soft pavement, which provides a basis for predicting the excitation characteristics of soft pavement.

(3) Due to the periodic characteristics of the arrangement of rectangular pit excitation points, the vibration acceleration signal and the effective roughness excitation signal have the generation of double frequency band. The highest point of vehicle vibration acceleration power value is concentrated at the frequency doubling and frequency doubling points, and the fundamental frequency amplitude of effective roughness excitation on soft road surface in the field is the highest. The results show that the maximum value of vehicle vibration acceleration response and the maximum value of field soft pavement excitation have a relationship of 2 or 3 times in frequency distribution, which provides reference for the prediction of pavement excitation frequency and the design of vehicle shock absorption. 
In this paper, the vehicle vibration response is used to evaluate the correlation between the excitation characteristics of the soft road surface and the vehicle vibration, but it is difficult to determine the effective wavelength range. Future plan will solve this issue by using the binocular visual odometer algorithm to obtain the spatial motion of the vehicle. A computer vision system will be developed to reduce the agriculture vehicles in the soft-filed roads.

\section{Data Availability}

All data that were used to produce the results in this paper are available from the corresponding author upon request.

\section{Conflicts of Interest}

The authors declare that they have no conflicts of interest.

\section{Acknowledgments}

This work was mainly supported by the National Natural Science Foundation of China (51565052) and part of the funding comes from the open project of Key Laboratory of Modern Agricultural Engineering (TDNG20170301) of Tarim University in Xinjiang Uygur Autonomous Region, China.

\section{References}

[1] M. Jiang, X. Hu, C. Joseph, Z. Lin, and R. Fei, "Does the popularization of agricultural mechanization improve energyenvironment performance in China's agricultural sector?," Journal of Cleaner Production, vol. 276, Article ID 124210, 2020.

[2] R. C. Ugras, O. K. Alkan, S. Orhan, M. Kutlu, and A. Mugan, "Real time high cycle fatigue estimation algorithm and load history monitoring for vehicles by the use of frequency domain methods," Mechanical Systems and Signal Processing, vol. 118, pp. 290-304, 2019.

[3] S. Milosavljevic, F. Bergman, B. Rehn, and B. Allan, "Carman. All-terrain vehicle use in agriculture: exposure to whole body vibration and mechanical shock," Applied Ergonomics, vol. 41, pp. 530-535, 2010.

[4] B. Mariotti, Y. Hoshika, M. Cambi et al., "Vehicle-induced compaction of forest soil affects plant morphological and physiological attributes: a meta-analysis," Forest Ecology and Management, vol. 462, Article ID 118004, 2020.

[5] P. R. Hargreaves, K. L. Baker, A. Graceson, S. Bonnett, B. C. Ball, and J. M. Cloy, "Soil compaction effects on grassland silage yields and soil structure under different levels of compaction over three years," European Journal of Agronomy, vol. 109, Article ID 125916, 2019.

[6] W. K. Carsten Hoever, "A model for investigating the influence of road surface texture and tyre tread pattern on rolling resistance," Journal of Sound and Vibration, vol. 351, pp. 161-176, 2015.

[7] R. Zhao, L. Hu, X. Luo et al., "A novel approach for describing and classifying the unevenness of the bottom layer of paddy fields," Computers and Electronics in Agriculture, vol. 162, pp. 552-560, 2019.

[8] Y. Qin, Z. Wang, C. Xiang, E. Hashemi, A. Khajepour, and Y. Huang, "Speed independent road classification strategy based on vehicle response: theory and experimental validation," Mechanical Systems and Signal Processing, vol. 117, pp. 653-666, 2019.

[9] Y. Qin, C. Wei, X. Tang, N. Zhang, M. Dong, and C. Hu, “A novel nonlinear road profile classification approach for controllable suspension system: simulation and experimental validation," Mechanical Systems and Signal Processing, vol. 125, pp. 79-98, 2018.

[10] M. A. Bidgoli, A. Golroo, H. S. Nadjar, A. G. Rashidabad, and M. R. Ganji, "Road roughness measurement using a costeffective sensor-based monitoring system," Automation in Construction, vol. 104, pp. 140-152, 2019.

[11] T. E. Putra, Husaini, and M. N. Machmud, "Predicting the fatigue life of an automotive coil spring considering road surface roughness," Engineering Failure Analysis, vol. 116, Article ID 104722, 2020.

[12] A. Kheirati and A. Golroo, "Low-cost infrared-based pavement roughness data acquisition for low volume roads," Automation in Construction, vol. 119, Article ID 103363, 2020.

[13] G. Xue, H. Zhu, Z. Hu et al., "Pothole in the dark: perceiving pothole profiles with participatory urban vehicles," IEEE Transactions on Mobile Computing, vol. 16, no. 5, 2016.

[14] W. Shi, M. Li, J. Guo, and K. Zhai, "Evaluation of road service performance based on human perception of vibration while driving vehicle," Journal of Advanced Transportation, vol. 2020, Article ID 8825355, 8 pages, 2020.

[15] L. Guo, T. Li, G. Chen, P. Yu, X. Peng, and D. Yang, “A method for microscopic unsaturated soil-water interaction analysis based on DDA," Computers and Geotechnics, vol. 108, pp. 143-151, 2019.

[16] L. Zheng, L. Mei, Y. Liu, Z. Zhang, and Y. Zhang, "A measuring equipment of terrain roughness and its dynamic characteristic analysis," Transactions of the Chinese Society for Agricultural Machinery, vol. 2, pp. 68-74, 1991.

[17] Y. Yin, L. Zheng, F. Gong, Y. Zhang, and J. Yin, "The principle of rough terrain excitation acting on vehicle wheels," Transactions of the Chinese Society for Agricultural Machinery, vol. 3, pp. 72-77, 1991.

[18] L. Zheng, Y. Cheng, L. Mei, Z. Zhang, and J. Yin, "Statistics analysis of the effective spectrum of the soft terrain surface," Transactions of the Chinese Society of Agricultural Engineering, vol. 4, p. 2027, 1991.

[19] L. Zheng, M. Liu, and Y. Zhang, "Formative process analysis of the effective spectrum of the soft terrain surface," Transactions of the Chinese Society of Agricultural Engineering, vol. 2, pp. 29-34, 1994.

[20] M. Liu, Y. Cheng, D. Wang, L. Zheng, Y. Zhang, and Z. Wang, "The theoretical trans form method of from original spectrum to effective spectrum of terrain," Transactions of the Chinese Society for Agricultural Machinery, vol. 4, pp. 11-17, 1993.

[21] Z. Fan, S. Li, F. Ma, L. Wan, L. Xiao, and B. Xue, "Simulation analysis and experiment on influence of road spectrum of cane field on cutting quality," Transactions of the Chinese Society of Agricultural Engineering, vol. 28, no. 1, pp. 37-41, 2012.

[22] S. Zhu, J. Ma, J. Yuan, G. Xu, Y. Zhou, and X. Deng, "Vibration characteristics of tractor in condition of paddy operation," Transactions of the Chinese Society of Agricultural Engineering, vol. 32, no. 11, pp. 31-38, 2016.

[23] Y. Yilidaer, S. Zhu, C. Minh, X. Nie, and G. Xu, "Study on vibration characteristics of tractor travel at the condition of marshy paddy soil," Journal of Nanjing Agricultural University, vol. 39, no. 6, pp. 1062-1068, 2016. 
[24] M. Cutini, C. Costa, and C. Bisaglia, "Development of a simplified method for evaluating agricultural tractor's operator whole body vibration," Journal of Terramechanics, vol. 63, pp. 23-32, 2016.

[25] C. Hu, X. Wang, S. Wang et al., "Impact of agricultural residual plastic film on the growth and yield of drip-irrigated cotton in arid region of Xinjiang, China," International Journal of Agricultural and Biological Engineering, vol. 13, no. 1, , 2020, https://www.ijabe.org.

[26] ISO 5008, Agricultural Wheeled Tractors and Field Machinery-Measurement of Whole-Body Vibration of the Operator, 2002.

[27] Y. Zhisheng, Vehicle Theory, Machinery Industry Press, Beijing, China, 3rd edition, 2004.

[28] J. Li, Z. Zhou, and L. Yan, "Test analysis of relationship between natural frequency and compaction degree for roadbed soil," Transactions of the Chinese Society of Agricultural Engineering, vol. 28, no. 14, pp. 71-76, 2012.

[29] J. Wang and X. Hu, Application of Matlab in Vibration Signal Analysis, China Water Resources and Hydropower Press, Intellectual Property Publishing House, Beijing, China, 2006.

[30] G. Wen, L. Yang, Y. Liao, and Q. He, "Faulty rotor system vibration acceleration signal integration method based on precise information reconstruction," Journal of Mechanical Engineering, vol. 49, no. 8, pp. 1-9, 2013.

[31] R. Deboli, A. Calvo, and C. Preti, "Whole-body vibration: measurement of horizontal and vertical transmissibility of an agricultural tractor seat," International Journal of Industrial Ergonomics, vol. 58, Article ID 69e78, 2017.

[32] S. Aisyah Adam and N. A. Abdul Jalil, "Vertical suspension seat transmissibility and SEAT values for seated person exposed to whole-body vibration in agricultural tractor preliminary study," Procedia Engineering, vol. 170, pp. 435-442, 2017.

[33] E. Zheng, X. Zhong, R. Zhu et al., "Investigation into the vibration characteristics of agricultural wheeled tractor-implement system with hydro-pneumatic suspension on the front axle," Biosystems Engineering, vol. 186, Article ID 14e33, 2019.

[34] H. Zhu, Y. Zhou, and Y. Hu, "Displacement reconstruction from measured accelerations and accuracy,control of integration based on a low-frequency attenuation algorithm," Soil Dynamics and Earthquake Engineering, vol. 133, Article ID 106122, 2020

[35] G. Liu, S.-x. Chen, and W.-d. Luo, "Synchronous sampling measuring method of the single-cycle RMS of motor nonsinusoidal power supply voltage," Electric Machines and Control, vol. 18, no. 1, pp. 112-116, 2014.

[36] Z. Lyu, J. Qian, Z. Shi, and Q. Gao, "Dynamic responses of layered poroelastic ground under moving traffic loads considering effects of pavement roughness," Soil Dynamics and Earthquake Engineering, vol. 130, Article ID 105996, 2020. 